Hepped, L. A. (1939). Amer. J. Physiol., 127, 385.

Holler, J. W. (1946). J. Amer. med. Ass., 131, 1186

Howard, J. E., Bigham, R. S., jun., Eisenberg, H., Wagrer, D., and Bailey, E. (1946). Bull. Johns Hopk. Hosp., 78, 282

Hunter. John (1794). A Treatise on the Blood, Inflammation, and Gunsho Wounds, p. 190 . G. Nicol, Lordon.

Ingle, D. J., and Thorn, G. W. (1941). Amer. J. Physiol., 132, 670.

Kolfi, W. J. (1950). J. Lab. clin. Med., 36, 719.

Landau, R. L., Knowiton, K.. Anderson, D., Brandt, M. B., and Kenyon, A. T. (1948). J. clin. Endocr., 8, 133 .

Maized, M. (1949). J. Physlol., 180, 247.

Marriott, H. L. (1951). Brittsh Medical Journal, 21284.

Mason, H. L., Power, M. H., Rynearson, E. H., Ciaramelli, L. C., LI C. H., and Evans, H. M. (1948). J. clin. Endocr., 8, 1.

Miller, H. C., and Darrow, D. C. (1940) Amer. J. Physiol 130747

Mullins, L. J., Fenn, W. O., Noonan, T. R., and Haege, L. (1941). Ibid., 135, 93

Prunty, F. T. G. (1949). J. clin. Invest., 28, 690.

Ringer, S. (1883). J. Physiol. $4,29$.

Roche, M., Thorn, G. W., and Hills, A. G. (1950). New Engl. J. Med. 242, 307 .

Selye, H. (1950). Stress. Montreal.

Sprague, R. G., Power, M. H., Mason, H. L., Albert, A., Mathteson, D. R. Hench, P. S., Kendall, E. G., Slocumb, C. H., and Polley, H. F. (1950) Arch, intern. Med $85,256$.

Stevenson, J. A. F., Schenker, V., and Browne, J. S. L. (1944). Endocrinology (Abstract), 35, 216.

Talbot. N. B., Saltzman, A. H., Wixom, R. L., and Wolfe, J. K. (1945). J. biol Chem 160, 535

Tarail, R., and Elkinton, J. R. (1949), J. clin. Invest. 28, 99.

Wilkinson, A. W., Billing, B. H., Nagy, G., and Stewart, C. P. (1949) Lancet, 1, 640.

(1950). Ibid., 2, 135.

Z - - - (1950). Ibid., 2, 1315.

Wilson, W. C., and Stewart, C. P. (1939). Edinb. med. J.. 46 (Trans. Med. Chir Soc. Bdinb) 153

Wright, Samson (1940). Applied Physiology. London.

\section{ANNULAR PANCREAS}

BY

B. F. SWYNNERTON, D.M., M.R.C.P.

Weir Research Assistant, Wandsworth Hospital Group

AND

\section{NORMAN C. TANNER, F.R.C.S.}

Senior Surgeon, St. James' Hospital, London

The commonest developmental abnormalities of the pancreas concern the ductal systems. Accessory pancreatic tissue-isolated masses separate from the main glandoccurs not infrequently in the stomach or duodenum, but may be found in most of the abdominal viscera. Other anomalies are pancreas divisum (Hyrtl) consisting of two separately functioning glands ; bifid tail of the pancreas; and annular pancreas in which a band of pancreatic tissue encircles the duodenum, usually in its second part. Cysts and fibrocystic disease may occur.

In 1933 McNaught was able to find descriptions of only 40 cases of annular pancreas in the literature, the first three referring to the condition in birds, in which it is apparently a normal finding (Ravitch and Woods, 1950). In June, 1952, the total number of cases recorded was at least 75, and it is significant to note that 20 of these have been recorded since the end of 1949 , indicating a higher actual incidence than the statistics show. In the absence of obstruction, cases may easily be overlooked either at operation or at necropsy.

A further case has recently been brought to light during an operation for chronic duodenal ulcer by one of us (N.C. T.).

\section{Case Report}

A male clerk aged 30 was admitted on October 13, 1951, with a history of two and a half years' epigastric pain two hours after meals, relieved by food, rest, and alkalis. There had been periods of freedom of up to nine months. He had no vomiting, but had lost $28 \mathrm{lb}$. $(12.7 \mathrm{~kg}$.) in weight since the onset. After investigation elsewhere he was told that a duodenal ulcer was present. The only abnormality detected was a gastric succussion splash. A gruel fractional test meal showed a high acid curve rising to $65 \mathrm{ml}$. N/10 free $\mathrm{HCl}$ at one hour.

A barium-meal examination disclosed a spastic deformed duodenal cap with folds radiating from an ulcer scar. There was no gross obstructive lesion of the second part of the duodenum. In view of his relapse despite more than one good course of medical treatment, he was operated upon on October 16. The presence of an anterior chronic duodenal ulcer was confirmed. The rest of the viscera appeared normal, except that, about $2-3 \mathrm{~cm}$. below the junction of the first and second parts of the duodenum, the organ was encircled by pancreatic tissue of healthy appearance and texture, the abnormal part being a band about 1-2 cm. in diameter (see illustration). A subhiatal vagot om y and Heineke - Mikulicz pyloroplasty was then carried out. During the pyloroplasty opportunity was taken to feel the duodenum from within its lumen, and there appeared to be no appreciable constriction. The

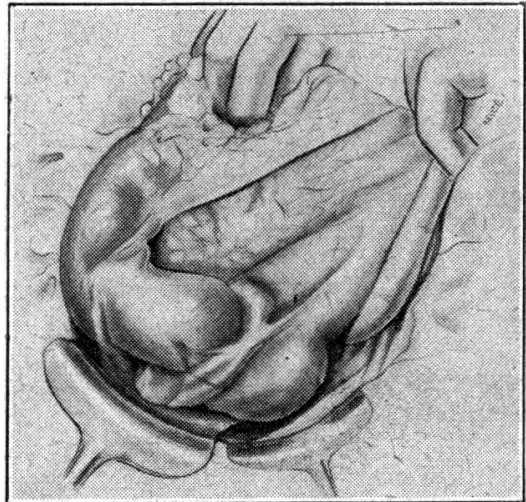

Diagram showing band of pancreatic tissue encircling the duodenum. patient made an uncomplicated recovery from this operation, and an insulin test meal 17 days later showed a much lower acidity and no secretory response to the insulin.

Nine months after operation the patient was symptomfree, and a further barium-meal examination showed no delay in emptying of the stomach and no evidence of constriction of the duodenum.

\section{Discussion}

Aetiology.-The condition affected males in 50 out of the 64 cases in which the sex was recorded. Various theories have been advanced concerning the embryological origin of the ring-for example, persistence of the left half of the ventral anlage of the pancreas which ordinarily atrophies, fixation of the ventral bud of the pancreas to the duodenum before rotation of the gut, or a smooth spread round the duodenum as is said to occur in birds. Other congenital abnormalities have been found associated with the annular pancreas in some 20 cases, the most frequent being malrotation of the abdominal viscera.

Symptomatology.-Patients with annular pancreas may present at any age with symptoms due to the condition, or the condition may be symptomless. The youngest recorded case was in a 16-mm. embryo (Weissberg, 1935), while two cases were operated upon at the age of 74 (Smetana, 1928 ; Custer and Waugh, 1944). Thirty-seven cases had symptoms due to the annulus. Most of the nine presenting in the first decade appeared shortly after birth, with symptoms of high intestinal obstruction or with jaundice probably due to compression of the common bile duct. If symptoms have not developed by this time it would seem reasonable to suppose that the patient has a good chance of remaining symptomfree throughout life. A study of the literature suggests that this is not the case. Adults usually present with high intestinal obstruction, with symptoms suggesting peptic ulceration, or, less commonly, with acute haemorrhagic pancreatitis. In the first there may be rapidly progressive or recurring episodes of obstruction. This sometimes results from pancreatitis of the annulus, but this is not a constant finding in those specimens which have been sectioned. Those patients with a history suggesting peptic 
ulceration may indeed have peptic ulcers as in the present case. Eight additional cases associated with peptic ulcers have been recorded (gastric 3, duodenal 5). Four further patients had a history of haematemesis or melaena. Acute haemorrhagic pancreatitis is a rare presentation, but has been recorded.

Differential Diagnosis.-The diagnosis has been suggested pre-operatively in eight cases. It will be considered only when there is a sufficient degree of deformity or obstruction to be shown by a barium-meal examination. Other possibilities to consider include congenital bands associated with malrotation, tumours of the pancreas or sphincter of Oddi, ulcer and rarely primary or secondary cancer of the second part of the duodenum, and pressure by enlarged glands from without.

Treatment.-If surgical treatment is indicated the choice of procedure lies between section of the ring and some form of by-pass operation. The former carries some risk of fistula formation, and so the site of division should be protected by a drain to the exterior. This may be combined with longitudinal division and transverse suturing of the duodenum, the suturing being made in such a way as to drain the cut ends of the pancreatic annulus into the lumen. This duodenoplasty overcomes any intrinsic duodenal narrowing and the possibility of recurrent obstruction. Partial gastrectomy is a somewhat severe method of dealing with an annular pancreas unassociated with other gastroduodenal disease. Gastro-jejunostomy introduces an undoubted risk of stomal ulceration, and, if feasible, duodenojejuncstomy would be preferable.

A case of annular pancreas is reported. The finding was an incidental one at operation for chronic duodenal ulcer. No obstruction of the duodenum was produced, and the presence of the condition did not affect the operative treatment of the ulcer.

We are indebted to Drs. R. Quilliam and A. Jenkins for the radiological reports and to Mrs. Mace for the picture.

REFERENCES

Custer, M. D., jun., and Waugh, J. M. (1944). Proc. Mayo Clin., 19, 388. McNaught, J. B. (1933). Amer. J. med. Sci., 185, 249.

Raviteh, M. M., and Woods, A. C., jun. (1950). Ann. Surg., 132, 1116

Smetana, H. (1928). Beitr. path. A nat., 80, 239.

Weissberg, H. (1935). Anat. Anz., 79, 296.

\section{SLIDING HERNIAS THROUGH THE OESOPHAGEAL HIATUS}

\author{
BY \\ G. RIOS-SOLANS, M.D.* \\ (From the Gardiner Institute of Medicine, University of \\ Glasgow)
}

\section{[With Special Plate]}

The anatomical abnormality of hernia through the diaphragm was first referred to in 1570 by Ambroise Paré, who noticed the condition at a post-mortem examination and attributed it to trauma. Fothergyll (1746) described a congenital variety. The first diagnosis during life was made by Newman (1888), who also performed the first operation for its cure. Akerlund (1933) made a careful study of all types of diaphragmatic hernia, and his classification has formed the basis for much subsequent work. In recent years the frequency of diaphragmatic or hiatus hernia has been fully recognized, and there are many publications available on the subject.

\footnotetext{
*Working as a scholar from Spain under the British Council.
}

The present paper deals with only one variety of hiatus hernia, the so-called "sliding hernia," which is the commonest of all, and which has been excellently described by Allison (1951). A sliding hiatal hernia is chiefly encountered in adults who are past middle age, and must therefore be regarded as quite distinct from a congenital defect. In considering its aetiology, two matters appear to be of prime importance: (1) the exact anatomical status of the so-called "cardia," or junction between oesophagus and stomach; and (2) the part played, structural and physiological, by the terminal part of the oesophagus as it passes through the diaphragm.

\section{The So-called "Cardia"}

In a study of the cardia, clarity in certain anatomical points is essential : $(a)$ the nature of the boundary between the oesophageal and gastric mucous membranes; $(b)$ the normal relationship of the boundary of the two mucous membranes to the exit through the diaphragm ; $(c)$ the question of a real anatomical sphincter at or close to the boundary; and $(d)$ the site of the change in shape from tubular (oesophagus) to saccular form (stomach). These points can be made out only by careful microscopical examination of the whole zone in specimens removed in the postmortem room and fixed by most careful technique to preserve and identify exact relationships. Macroscopic methods such as changes in colour, difference of shape, and even $x$-ray films taken during life are not exact enough, and may indeed be very misleading. Oesophageal structure is clearly identified microscopically by its stratified squamous epithelium, and stomach structure by its characteristic mucous membrane. Microscopical investigation clearly shows that the junction of the two mucous membranes is not a ring, but follows an irregular curve. Moreover, although the junction of the two mucous membranes is clean-cut, it is not unusual to find areas of gastric mucosal glands lying below the stratified oesophageal lining membrane. The opposite, however, does not occur.

In the photomicrograph (see Plate) this transition is clearly seen, and the two muscular layers are also well demonstrated. The point should also be noted, as has been found microscopically, that the diaphragmatic muscle does not clasp the oesophagus at a fixed level or point-there is an agglomeration of muscle fibres and loose fibrous tissue which allows the oesophagus to slide up and down for a short distance, this being essential for the normal respiratory movement of the diaphragm. In what may here be termed normal cases, accurate marking showed that the level of the diaphragmatic insertion and the junction of the two mucosae never coincided. Oesophageal stratified epithelium was always found at this level, indicating that the normal junction is below the diaphragm and just above the point where the saccular expansion of the stomach begins. This explains the curious observation that carcinoma of the fornix of the stomach extends to the cardia. That is to say, it invades the lowest tubular portion, with resultant incompetence or stenosis. No observation has been made of a carcinoma of the oesophagus (properly called) subsequently invading the fornix. It would seem, therefore, that a tumour always infiltrates the same structure and the change of lining membrane constitutes a barrier. A gastric carcinoma which invades the lowest tubular part invades its own structure, not the oesophagus.

\section{Terminal Part of the Oesophagus}

No evidence was found microscopically of any true muscular sphincter at the lower end of the oesophagus. As has been stated, the joining line between the two mucosae is an irregular curve and never a ring, and a ring form would almost be required for a true muscular sphincter. Thus, as Barrett (1952) has pointed out, the cardia and sphincter mechanism are not synonymous. 